Asian Spine Journal Vol. 6, No. 3, pp 219 219, 2012

http://dx.doi.org/10.4184/asj.2012.6.3.219

\title{
Treatment of Acute Tuberculous Spondylitis by the Spinal Shortening Osteotomy: A Technical Notes and Case Illustrations
}

\author{
Mohamed El-Sayed Abdel-Wanis \\ Department of Orthopaedic Surgery, Sohag Faculty of Medicine, Sohag University, Sohag, Egypt
}

\section{Dear Sir,}

I read with great interest the paper published in your journal entitled "Treatment of acute tuberculous spondylitis by the spinal shortening osteotomy: technical notes and case illustrations." by Chanplakorn et al. [1]. In this paper the authors reported: "However, to the best of our knowledge, there is no report on spinal shortening ostotomy as a surgical treatment for the active disease stage of tuberculous spondylitis without a severe rigid angular kyphotic deformity" [1]. I am sending you this letter in order to clarify that the first research work reporting single stage posterior debridement of active spinal infections with anterior reconstruction performed by limited spinal shortening was completed by me in 2006 [2]. Within the paper I published my first experience with posterior single stage debridement and fusion for thoracic and lumbar spine infections in 12 patients. In 5 out of 12 patients, anterior reconstruction was performed utilizing limited spinal shortening ( 2 in the thoracic spine and 3 in the lumbar spine). In my study, Fig. 1 demonstrated a case of tuberculous (TB) spondylitis of the thoracic spine (Th8-9) similar to the cases presented by Chanplakorn et al. and the anterior defect was reconstructed through limited spinal shortening [2]. In SICOT 2011 XXV Triennial World Congress, held during September 6-9, 2011 in Prague, Czech Republic, I reported my experience in 10 patients of infections of the thoracic spine treated by the same technique with anterior reconstruction done in all cases by spinal shortening (abstract number 29530). The age of the patients ranged between 35 and 71 years with a mean age of 56.5 years. Causative organisms were TB in 8 patients, Staph aureus in 1 patient and bacteriologic testing of intraoperative samples did not find germs in 1 patient. The mean follow-up was 30.7 months (range, 5 to 80 months). Seven patients demonstrated neurological improvement. Two complications were encountered; kyphosis progression and temporary neurological deterioration [3].

\section{REFERENCES}

1. Chanplakorn P, Chanplakorn N, Kraiwattanapong C, Wajanavisit W, Laohacharoensombat W. Treatment of acute tuberculous spondylitis by the spinal shortening osteotomy: a technical notes and case illustrations. Asian Spine J 2011;5:237-44.

2. Abdel-Wanis ME. Single-Stage posterior circumspinal debridement and reconstruction for thoracic and lumbar spinal infections. J Musculoskel Res 2006;10:173-80.

3. Abdel-Wanis ME. Posterolateral debridment and anterior reconstruction by limited spinal shortening in thoracic spine infections. Presentation at SICOT 2011 XXV Triennial World Congress; 2011 September 6-9; Prague, Czech Republic.

Received Apr 30, 2012; Revised May 1, 2012; Accepted May 1, 2012

Corresponding author: Mohamed El-Sayed Abdel-Wanis, MD, PhD

Department of Orthopaedic Surgery, Sohag Faculty of Medicine,

Sohag University, Sohag, PO 82524, Egypt

Tel: 0020-93-2334727,0020-93-2318158,E-mail: wanis307@yahoo.com

Copyright (C) 2012 by Korean Society of Spine Surgery

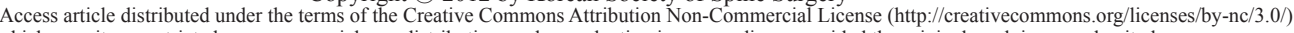
which permits unrestricted non-commercial use, distribution, and reproduction in any medium, provided the original work is properly cited. Asian Spine Journal • pISSN 1976-1902 eISSN 1976-7846 